\title{
ESTUDO DA PIRÓLISE DE RESINAS DENTÁRIAS A BASE DE POLI(METACRILATO DE METILA)
}

\author{
L. F. RODRIGUES ${ }^{1}$, M. C. SANTOS ${ }^{2}$, H. J. S. RIBEIRO ${ }^{2}$ e N.T. MACHADO ${ }^{1}$ \\ ${ }^{1}$ Universidade Federal do Pará, Instituto de Tecnologia, Faculdade de Engenharia Química \\ ${ }^{2}$ Universidade Federal do Pará, Programa de Pós Graduação em Engenharia de Recursos \\ Naturais \\ E-mail para contato: lilianfavacho@hotmail.com
}

\begin{abstract}
RESUMO - Em prol do crescente consumo de materiais plásticos, a maioria produzidos a partir de matérias-primas derivadas do petróleo, a disposição final de seus resíduos não biodegradáveis ganhou maior visibilidade. Nesse contexto, esse trabalho investigou o processo de recuperação química de resíduos dentários à base de poli (Metacrilato de Metila), PMMA, via pirólise em unidade de bancada, com o objetivo de obter o seu monômero, metacrilato de metila (MMA). Os experimentos foram realizados a 350,400 e $450^{\circ} \mathrm{C}$, utilizando-se um reator cilíndrico de vidro boro-silicato de $100 \mathrm{~mL}$, inserido em um forno cilíndrico de resistência cerâmica e controle digital de temperatura e taxa de aquecimento. A reação produziu gases não condensáveis, uma fase líquida e uma fase sólida. Assim, foi avaliada a influência da temperatura de craqueamento no rendimento e na qualidade das frações líquidas, por meio da caracterização físico-química (refração, densidade e viscosidade) e posterior comparação com as características do monômero comercial (virgem). Os resultados indicam que o aumento da temperatura elevou o rendimento da fase líquida e diminuiu o da fase sólida. As características de refração, densidade e viscosidade das frações líquidas são similares às do MMA. Portanto, é possível recuperar grandes quantidades de fração líquida com características próximas às do MMA comercial, cerca de $90 \%$, a partir do resíduo da indústria dentária.
\end{abstract}

\section{INTRODUÇÃO}

Os plásticos são materiais poliméricos, conjuntos de macromoléculas constituídas por unidades estruturais que se repetem (monômeros), utilizados em larga escala, nos mais variados setores de atividade (Bras, 2011). Devido à diversidade de propriedades e à facilidade de processamento, os polímeros se tornaram indispensáveis ao cotidiano.

O poli (Metacrilato de Metila) - PMMA é um importante tipo de termoplástico utilizado em aplicações como folhas transparentes, isolante elétrico, unidades de casa, peças automotivas, revestimento de superfície, resinas de troca iônica, indústria produtora de materiais dentários (Achilias, 2006). Quando submetido à pirólise, o PMMA sofre despolimerização, resultando na produção do monômero inicial, o metacrilato de metila (MMA) (Braido, 2014). 
A pirólise de PMMA é descrita na literatura como um dos processos para a reciclagem termoquímica desse polímero, que, conforme relatado por Achilias (2007), possibilita a recuperação em torno de $97 \%$ do monômero metacrilato de metila (MMA), a temperaturas entre 400 e $500^{\circ} \mathrm{C}$. O produto líquido obtido na etapa de pirólise pode ser polimerizado novamente, entretanto, podem conter impurezas devido a componentes da mistura, como pigmentos e outros aditivos. Assim, o monômero deve ser purificado, com a destilação, por exemplo, para a produção de novos polímeros (Szabo, 2011).

$\mathrm{Na}$ produção de dentes de plástico aproximadamente $80 \%$ do polímero (PMMA) produzido é descartado (Braido, 2014). Nesse contexto, o presente trabalho propõe-se a investigar o processo de despolimerização dos resíduos da indústria produtora de materiais dentários à base de PMMA via pirólise, em unidade de Escala de Bancada.

\section{MATERIAIS E MÉTODOS}

\subsection{Unidade em Escala de Bancada}

As aparas de PMMA, oriundas da produção de dentes para próteses dentárias, foram fornecidas pela Dentsply Indústria e Comércio LTDA. Os experimentos de pirólise foram realizados em Unidade em Escala de Bancada, constituída por um reator de vidro borosilicato, com capacidade volumétrica de $100 \mathrm{~mL}$ e dimensões $15 \mathrm{~cm}$ de altura e $4,0 \mathrm{~cm}$ de diâmetro interno. Inicialmente, uma massa equivalente a $40 \mathrm{~g}$ de PMMA triturado (Figura 1) foi pesada e acondicionada no reator que, por sua vez, foi inserido em um forno cilíndrico de resistência cerâmica conectada ao controlador digital de temperatura e taxa de aquecimento. Acoplado ao reator foi utilizada um tubo de ligação de vidro borossilicato no formato de Y. A corrente líquida foi coletada em um balão de fundo redondo, com capacidade de $50 \mathrm{~mL}$, colocado em um béquer contendo "cubos" de gelo submergido em água destilada para condensar a fração líquida obtida. A rampa de temperatura foi definida em $10^{\circ} \mathrm{C} / \mathrm{min}$, partindo da temperatura ambiente. O tempo de reação do processo foi iniciado a partir do instante em que o sistema alcançava a temperatura de reação desejada. Os experimentos foram realizados em duplicata, em que o parâmetro variado foram as temperaturas de operação $\left(350,400\right.$ e $\left.450^{\circ} \mathrm{C}\right)$.

Figura 1 - a) Aparas dentárias a base de PMMA como recebidas, b) PMMA triturado no reator.
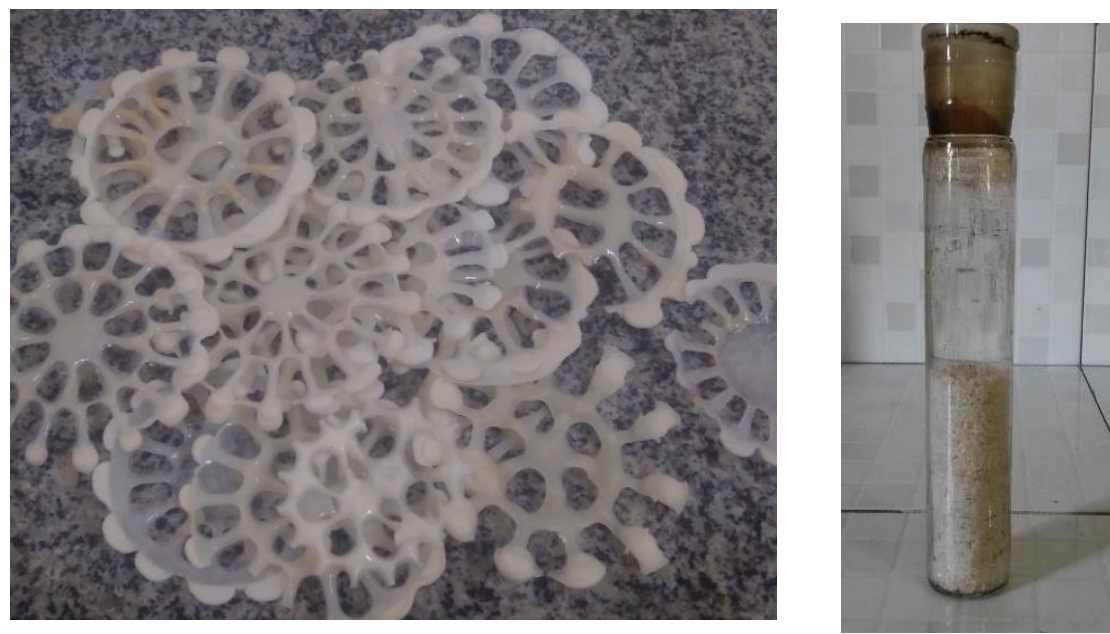


\subsection{Cálculo de Rendimento}

O rendimento, $\eta$, foi calculado pela Equação 1, em que m é a massa do produto craqueado e $\mathrm{m}_{\mathrm{T}}$ é a massa inicial de PMMA colocada no reator.

$$
\eta=\frac{m}{m_{T}}
$$

\subsection{Caracterização das frações líquidas}

A caracterização das frações líquidas obtidas na pirólise de PMMA foi realizada de acordo com os métodos padrões estabelecidos por Normas Brasileiras (NBR) da Associação Brasileira de Normas Técnicas (ABNT) ou de Normas da American Society for Testing and Materials (ASTM). A densidade relativa foi determinada pelo método de picnometria, conforme o método ASTM D4052. A Viscosidade Cinemática foi determinada segundo a norma ASTM D 445 (2006) e o Índice de refração foi determinado de acordo com o método oficial AOCS Cc 7-25 (1997).

\section{RESULTADOS E DISCUSSÕES}

Durante a pirólise em Unidade de Bancada observou-se que o início da condensação do material ocorreu em temperaturas próximas de $215^{\circ} \mathrm{C}$, e intensificou-se a partir de $250^{\circ} \mathrm{C}$. Essa faixa de temperatura está de acordo com a temperatura de degradação térmica do PMMA (Achilias, 2007). Os dados referentes aos rendimentos dos experimentos realizados em Unidade de Bancada estão dispostos na Figura 2.

Figura 2 - Rendimento pirólises em Unidade de Bancada.

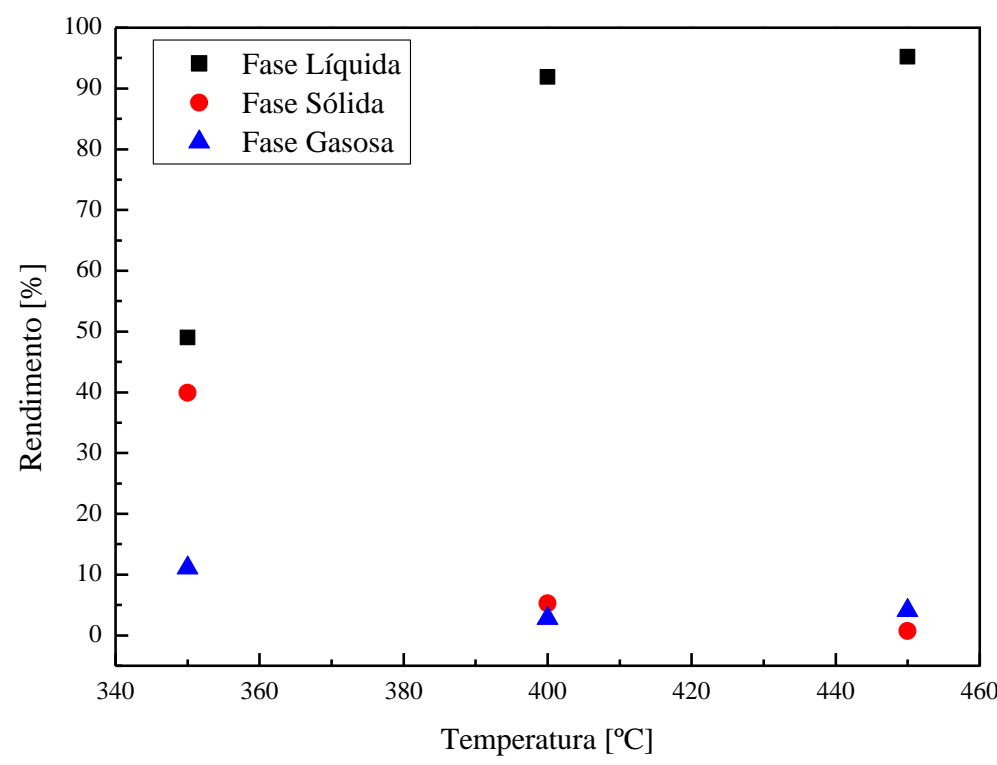


Figura 3 - MMA e frações líquidas obtidas por craqueamento térmico a 350, 400 e $450^{\circ} \mathrm{C}$, respectivamente

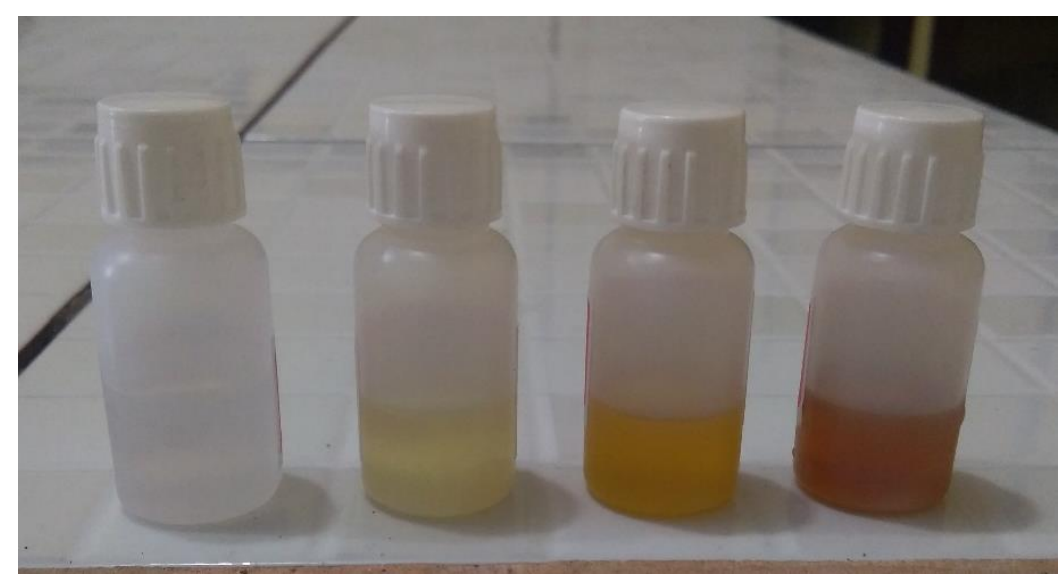

De acordo com a Figura 2, o rendimento médio das frações líquidas obtidas nos experimentos para as temperaturas de 350,400 e $450^{\circ} \mathrm{C}$ foram, respectivamente, $49 \% ; 91,88 \%$ e $95,19 \%$. O rendimento das frações líquidas aumentou com o aumento de temperatura, enquanto que o rendimento da fase sólida diminui. Assim, destacou-se o experimento realizado na temperatura de $450^{\circ} \mathrm{C}$. É importante ressaltar que, apesar de maior rendimento de fração líquida, esse experimento teve maior formação de produto gasoso, quando comparado com a pirólise realizada a $400^{\circ} \mathrm{C}$, pois o aumento da temperatura também levou ao aumento da produção de gases. Conforme mostra a Figura 3, observou-se que os líquidos produzidos ficaram mais escuros com a elevação da temperatura, que indica a ocorrência de carbonização do sólido, segundo Braido (2014).

Foram avaliadas as características físico-químicas das frações líquidas da pirólise em Unidade de Bancada e do monômero comercial (virgem). Os resultados estão na Tabela 1.

Tabela 1 - Caracterização das frações líquidas

\begin{tabular}{c|c|c|c}
\hline Caracterização & Refração & Densidade $\left(\mathrm{g} / \mathrm{cm}^{3}\right)$ & Viscosidade $(\mathrm{cSt})$ \\
\hline Exp. $1-$ T. $350^{\circ} \mathrm{C}$ & 1,42 & 0,945 & 0,556 \\
\hline Exp. $2-$ T. $400^{\circ} \mathrm{C}$ & 1,42 & 0,947 & 0,591 \\
\hline Exp. $3-$ T. $450^{\circ} \mathrm{C}$ & 1,42 & 0,948 & 0,595 \\
\hline Monômero Virgem & 1,41 & 0,937 & 0,570 \\
\hline
\end{tabular}

A partir dos dados da Tabela 1 observa-se que os produtos líquidos apresentaram índice de refração igual ao do monômero MMA. Em relação a densidade, os experimentos resultaram em produtos com densidade maior que a do MMA, em que destaca-se o experimento a $350^{\circ} \mathrm{C}$ com densidade mais próxima à do monômero (aproximadamente $0,94 \mathrm{~g} / \mathrm{cm}^{3}$ ). Nas análises de 
viscosidade cinemática os experimentos 2 e 3 (temperaturas de 400 e $450^{\circ} \mathrm{C}$ ) apresentaram valores maiores que o medido para o MMA e o experimento 1 apresentou valores menores. Portanto, verificou-se que as características dos produtos líquidos obtidos por pirólise em Escala de Bancada estão de acordo com as características do monômero comercial.

É importante destacar que no experimento 1 obteve-se o produto líquido com as características mais próximas às do MMA, apesar do menor rendimento do processo, devido a carbonização do sólido que ocorre com o aumento da temperatura de pirólise, diminuindo a porcentagem de monômero no produto líquido.

\section{CONCLUSÃO}

Os resultados revelam que é possível recuperar grades quantidades de frações líquidas com características similares às do monômero comercial MMA (cerca de $90 \%$ ) a partir do resíduo da fabricação de próteses dentárias à base de PMMA. Os experimentos em unidade em Escala de Bancada demonstraram que o aumento da temperatura eleva o rendimento do produto líquido e consequentemente diminui o rendimento do produto sólido. Entretanto, o aumento da temperatura ocasionou um aumento na produção de gases não condensáveis. Além disso, pode ocasionar a produção de líquidos indesejados e de carbono durante a pirólise, o que é verificado na coloração do produto líquido, que escurece com o aumento da temperatura.

Os experimentos realizados a temperatura de $450^{\circ} \mathrm{C}$ apresentaram o melhor rendimento de produto líquido, cerca de $95 \%$. Entretanto, os experimentos a $350^{\circ} \mathrm{C}$ obtiveram os produtos com características físicas mais próximas às do monômero MMA, devido a carbonização do sólido que ocorre com o aumento da temperatura de pirólise. Dessa forma, a próxima etapa consiste em realizar a purificação dos produtos líquidos obtidos a partir da pirólise do PMMA, pelo processo de destilação.

\section{REFERENCIAS}

ACHILIAS, D. S. Chemical recycling of poly(methyl methacrylate) by pyrolysis. Potential use of the liquid fraction as a raw material for the reproduction of the polymer. European Polymer Journal, Volume 43, Issue 6, 2007, p. 2564-2575.

ACHILIAS, D. S. Chemical Recycling of Polymers. The Case of Poly(methyl methacrylate). International Conference on Energy \& Environmental Systems, Chalkida, p. 271-276, Greece, 2006.

ACHILIAS, D. S.; ROUPAKIAS, C.; MEGALOKONOMOSA, P.; LAPPAS, A. A.; ANTONAKOU, E.V. Chemical recycling of plastic wastes made from polyethylene (LDPE and HDPE) and polypropylene (PP). Journal of Hazardous Materials, Volume 149, Issue 3, 2007, p. 536-542.

BRAIDO, R. S. Pirólise de resinas dentárias à base de poli(Metacrilato de Metila). 2014. 147 f. Dissertação (Mestrado em Engenharia Química) - Pós-Graduação e Pesquisa de Engenharia (COPPE), Universidade Federal Do Rio De Janeiro. Rio de Janeiro, 2014.

BRÁS, D. M. Estudo da Pirólise de Resíduos Plásticos provenientes do Abate de Automóveis. 2011. 144 f. Dissertação (Mestrado em Energia e Bioenergia) - Faculdade de Ciência e Tecnologia, Universidade Nova de Lisboa. Lisboa, 2011. 
SZABO, E.; OLAH, M.; RONKAY, F.; MISKOLCZI, N.; BLAZSO, M. Characterization of the liquid product recovered through pyrolysis of PMMA-ABS waste. J. of Analytical and Applied Pyrolysis, Volume 92, Issue 1, 2011 